УДК 373

\title{
ТЕОРЕТИЧЕСКИЕ ОСНОВЫ ФОРМИРОВАНИЯ ЗДОРОВЬЕСБЕРЕГАЮЩЕЙ СРЕДЫ ДОШКОЛЬНОЙ ОБРАЗОВАТЕЛЬНОЙ ОРГАНИЗАЦИИ
}

\section{Компанец Гульсум Акимовна}

студент

Евпаторийский институт социальных наук (филиала)

ФГАОУ ВО «КФУ им. В. И. Вернадского»

Аннотация. Данная статья посвящена актуальной проблеме формирования здоровьесберегаюшей среды образовательной организации. По результатам исследования можно отметить, что в литературных источниках авторы описывают современные подходы к формированию здоровьесберегающей среды образовательного учреждения. Также авторы описывают принципы и закономерности, на которых должна базироваться деятельность по формированию здоровьесберегающей среды образовательной организации. Авторы предлагают парадигму формирования здоровьесберегающей среды. Особое внимание авторами было уделено оценке эффективности деятельности, доступно описываются показатели и критерии формирования здоровьесберегающей среды.

Ключевые слова: здоровьесберегающая среда, закономерности и принципы здоровьесберегающей среды, парадигма формирования здоровьесберегающей среды, показатели и критерии формирования здоровьесберегающей среды.

Abstract. This article is devoted to the actual problem of forming a healthpreserving environment of an educational institution. Based on the analysis of research in the literature, the authors describe modern approaches to the formation of a health-preserving environment of an educational institution. As for the idea of health-preserving environment pedagogy, the authors describe the laws and principles that should be used to form the health-preserving environment of an educational institution. In these ideas, the authors propose a paradigm for the formation of a health-preserving environment, which is defined in the description of its application as theoretical, application of conditions, meaningful and effective. The 
authors paid special attention to the assessment of performance, which clearly describes the indicators and criteria for the formation of a health-saving environment.

Key words: health-preserving environment, regularities and principles of health-preserving environment, paradigm of health-preserving environment formation, indicators and criteria of health-preserving environment.

Постановка проблемы. Формирование здорового подрастающего поколения - одна из главных стратегических задач развития страны. Сегодня стратегическое направление государственной политики в области поддержки и сохранения здоровья детей обеспечивается и регламентируется рядом нормативно-правовых документов. Это Закон Российской Федерации «Об образовании», где определены принципы государственной политики в области образования, первым из которых является «гуманистический характер образования, приоритет общечеловеческих ценностей жизни и здоровья человека, свободного развития личности», а также Закон РФ «О санитарноэпидемиологическом благополучии населения»; Указы Президента России «О неотложных мерах по обеспечению здоровья населения в Российской Федерации», «Об утверждении основных направлений государственной социальной политики по улучшению положения детей в Российской Федерации», Закон РФ «О физической культуре и спорте», «Конвенция о правах ребенка».

Анализ исследований и публикаций. Анализ работ А.Р. Вирабовой, С.С. Ивановой, И.В. Непрокиной, Н.Т. Рыловой, И.А. Степановой, Л.В. Судоргиной, Г.И. Тушиной и других авторов позволил сделать вывод о том, что здоровьесберегающую, образовательную среду на сегодняшний день рассматривают в междисциплинарном контексте, а определение данного понятия не имеет завершенного педагогического толкования.

Целью статьи является: обосновать понятие «здоровьесберегающая среда».

Изложение основного материала. Несмотря на достаточную изученность данной проблемы, следует отметить, что ряд вопросов остаётся открытым, следует подчеркнуть необходимость её более глобального изучения.

Первые шаги на пути к стремлению вести здоровый образ жизни, самопознанию, развитию культуры здоровья происходят в дошкольной организации. Оттого, насколько грамотно и правильно организована работа с 
детьми по сбережению здоровья, насколько эффективно и результативно используются для этого условия образовательной организации, зависит состояние здоровья детей.

Прежде чем рассмотреть понятие «здоровьесберегающая среда», следует определить понятие «среда». М.Я. Басов определяет среду как отрезок действительности, в связи с которым живет человек и его отношения, которые являются жизненно значимыми для него [с.432.].

Здоровая среда обучает, воспитывает, формирует представление о мире в сознании ребенка и остается как основа культуры человека и общества в целом. Невысокий процент заболеваемости детей и окружающих их взрослых автоматически становится показателем компетентно построенной среды, в которой обучаются и воспитываются дети и находятся взрослые.

Что же касается здоровьесберегающей среды, «это благоприятная среда обитания и деятельности человека, а также окружающие его общественные, материальные и духовные условия, оказывающие положительное влияние на его здоровье». Здоровьесберегающая среда обеспечивает благополучное развитие ребенка, и способствует его успешной социализации. Изучение проблемы процесса социализации, а также здоровьесберегающей среды как фактора социализации не теряет своей актуальности. Процесс развития будет протекать успешно, только если личность будет физически, социально и психически здорова.

Проблемы укрепления здоровья и долголетия волновали выдающихся деятелей науки и культуры всех народов во все времена. Извечен был вопрос о том, как человеку преодолеть все неблагоприятные влияния окружающей среды на организм и сохранить хорошее здоровье, быть физически крепким, сильным и выносливым, чтобы прожить долгую и творчески активную жизнь. Таким образом, здоровьесберегающая среда является гибкой, развивающей системой, основой которой является эмоционально-комфортная среда пребывания и благоприятный режим организации жизнедеятельности детей.

T.B. Климова дает следующую формулировку понятию «здоровьесберегающая среда» - это здоровое психолого-педагогическое пространство в образовательной организации. Это комплекс, организуемый администраций образовательной организацией, всем педагогическим коллективом при обязательном участии самих воспитанников и их родителей в целях обеспечения охраны и укрепления здоровья воспитанников, создания 
благоприятных условий для профессиональной образовательной деятельности [c. 30-37].

Среди различных видов образовательных сред, авторы выделяют здоровьесберегающую среду под которой понимают:

- социально организуемую образовательную среду, в которой провозглашается здоровый образ жизни, сформирована система воспитания культуры здоровья, прогнозируется здоровьесберегагощая деятельность на интегративной основе (О.Е. Подгорная [2, с. 15]);

- условия, обеспечивающие гармоничное интеллектуальное, физическое, духовнонравственное развитие субъектов педагогического процесса, формирование у них потребности в здоровом образе жизни (Г.Н. Сериков [c. 242]);

- сложноорганизованную, многофакторную подсистему, включающую ценностно-смысловой, социокультурный, нормативно-правовой, организационно-управленческий и организационно-педагогический, гигиенический и медико-профилактический, физкультурно-оздоровительный, социально-психологический и психолого-педагогический, диагностический и коррекционный компоненты» (В.Е. Цибульникова [4, с. 161]).

Для того чтобы выявить проблемы создания здоровьесберегающей среды в дошкольной образовательной организации, необходимо рассмотреть ряд понятий и условий, связанных с указанным вопросом. Здоровьесберегающую среду авторы Ж.В. Шарафуллина, С.А. Уланова раскрывают как уклад деятельности образовательной организации, который поддерживает ЗОЖ её субъектов и способствует их саморазвитию при осознании ценности здоровья; в структуре здоровьесберегающей среды авторами выделены предметнопространственный, организационно-стратегический и коммуникативнотехнологический компонент [c.213].

По определению, которое дает Т.В. Климова, здоровьесберегающая среда по отношению к детям дошкольного возраста включает в себя «комплексное пространство»: социально-гигиенических, психолого-педагогических, морально-этических, экологических, физкультурно-оздоровительных, образовательных системных мер, обеспечивающих ребенку психическое и физическое благополучие, комфортную, морально-нравственную и бытовую среду в семье и дошкольной организации.

Л.Н. Волошина [с.294] указывает, что сущность здоровьесберегающего образовательного пространства характеризуют его формируемость, 
полицентричность, концентричность, открытость, управляемость, вариативность, структурность.

Авторами были определены основные направления для создания оптимального здоровьесберегающего пространства, следующим образом:

- создание оптимального управленческого механизма, обеспечивающего мотивированное и директивное участие всех субъектов образовательного процесса в подготовке конкурентно-способных специалистов в условиях здоровьесбережения;

- создание нормативной базы учебного заведения, закрепляющей права и обязанности каждого участника образовательного процесса по сохранению и укреплению здоровья;

- создание материально-технической базы в соответствии с санитарногигиеническими нормами и правилами: содержание и функционирование объекта, обеспечение рационального и сбалансированного питания, организация медицинского обслуживания;

- систематическое обучение субъектов образовательного процесса правилам техники безопасности;

- проведение диагностики психофизического состояния детей и педагогов и его психолого-педагогическая оценка для утверждения здорового образа жизни как формы бытия;

- обучение педагогов и сотрудников навыкам сохранения и укрепления здоровья своего и в том числе окружающих;

- оптимальная физиологически оправданная организация учебного процесса; учебно-методическое обеспечение, соответствующее разным адаптационным способностям учеников; коррекция содержания образования;

- формирование физической культуры как фактора гармоничного развития физических и духовных качеств личности, организация групп для занятия физкультурой лиц с различной патологией [2].

Образовательную среду О.В. Кузнецова определяет, как: «совокупность теоретических и практических образовательных ресурсов (включая и организационные), обеспечивающих рост благополучия, обогащение возможностей, формирование личности и направленное ее развитие, а также предотвращение проблем у всех участников образовательного процесса» [c.15].

Таким образом, ряд авторов выделяют характеристики понятия «здоровьесберегающая образовательная среда» (Таблица 1) 
Таблица 1

Характеристики понятия «здоровьесберегающая образовательная среда»

\begin{tabular}{|l|l|}
\hline И.П. Андриарди & $\begin{array}{l}\text { «Это совокупность управленческих, организационных, } \\
\text { педагогических условий, направленных на формирование, } \\
\text { укрепление и сохранение социального, психологических и } \\
\text { медико-физиологических средств и методов } \\
\text { сопровождения образовательного процесса, профилактики } \\
\text { факторов «риска», реализации комплекса } \\
\text { межведомственных оздоровительных мероприятий» [5] }\end{array}$ \\
\hline $\begin{array}{l}\text { Э.М. Казин, Касаткина } \\
\text { Т.Н. Семенкова }\end{array}$ & $\begin{array}{l}\text { «Совокупность организационно-педагогических и } \\
\text { социально-гигиенических условий, психолого- } \\
\text { физологических факторов, способствующих реализации } \\
\text { возможностей индивида, укреплению, сохранению, } \\
\text { психологического и физиологического здоровья } \\
\text { обучающихся, социализации и самоактулизации } \\
\text { личности». [2011. 10 (112)]. }\end{array}$ \\
\hline Ж.В. Шара- & $\begin{array}{l}\text { Особый уклад деятельности образовательной } \\
\text { организации, который поддерживает здоровый образ } \\
\text { жизни ее субъектов и содействует их саморазвитию в } \\
\text { получении ценности здоровья. [213, с. 81] }\end{array}$ \\
\hline Р.А. Касимов & $\begin{array}{l}\text { Определенные условия для эффективного } \\
\text { функционирования здоровьесберегающих социальных, } \\
\text { педагогических, психологических, медицинских и других } \\
\text { программ, технологий, планов, а также объекты и } \\
\text { средства здоровьясбережения, представляющие } \\
\text { возможности для взаимодействия субъектов } \\
\text { образовательного пространства с целью укрепления и } \\
\text { сохранения здоровья субъектов образовательного } \\
\text { процесса и формирования здорового образа жизни у них. } \\
\text { [с.1б2] }\end{array}$ \\
\hline
\end{tabular}

Анализ содержания понятия позволяет нам определить, что авторы (И.П. Андриади, Э.М. Казин, Н.Э Касаткина, Р.А. Касимов, Т.Н. Семенкова) сошлись во мнении, что здоровьесберегающая образовательная среда - это совокупность условий (организационных, управленческих, педагогических, 
социальных, гигиенических, медицинских) внутри образовательной организации, обеспечивающих здоровье обучающихся.

В настоящее время дошкольные образовательные организации являются ведущим институтом, содержание и направление деятельности которых регулируется федеральным государственным образовательным стандартом дошкольного образования (ФГОС ДОО), содержащим совокупность обязательных требований к структуре, объему, условиям и результатам реализации основной образовательной программы.

М.Н. Берулава утверждает, «что на современном этапе реализации развивающее обучение в случае недостаточного уровня теоретикометодической подготовки педагогов, а также для воспитанников с невысоким уровнем возрастного психического развития и для детей с доминированием образно-чувственного восприятия мира оказывается дезадаптивным и наносящим вред здоровью детей» [с. 31].

Для изучения условий реализации функции сохранения и укрепления здоровья детей образовательными организациями и определение ведущих характеристик здоровьесберегающей среды установлены критерии и показатели для отслеживания эффективности деятельности образовательных организаций. Разработанные критерии оценки эффективности здоровьесберегающей педагогической деятельности в образовательной организации позволяют выделить: медицинский, дидактический, воспитательный. (Рисунок 1).

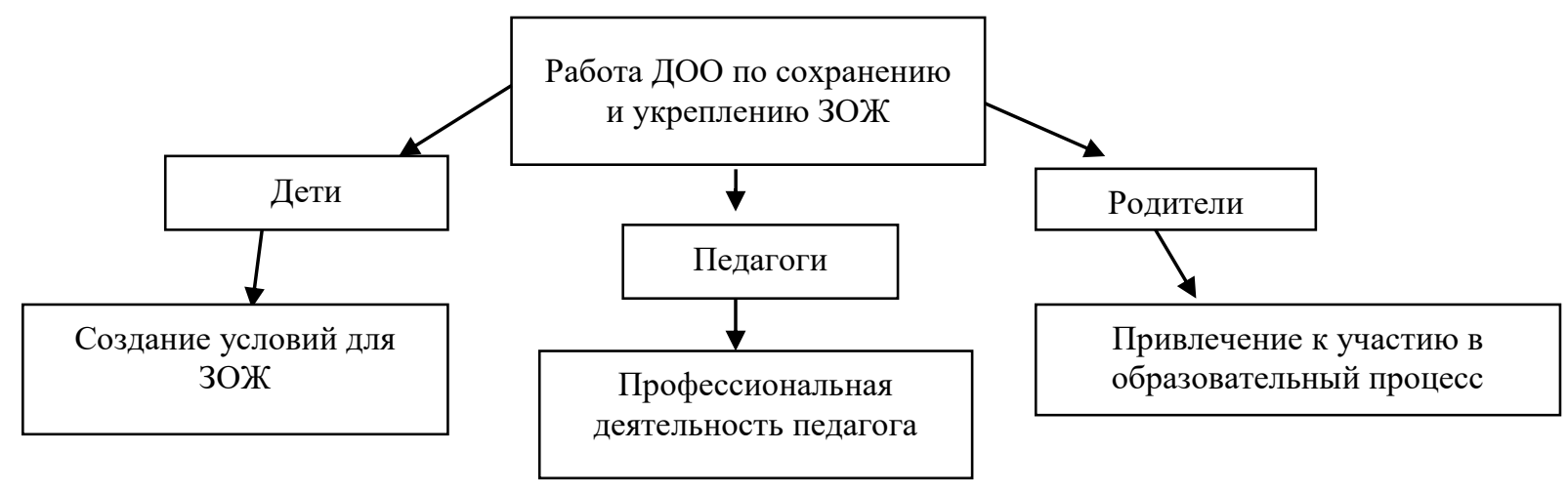

\section{Рис. 1. Здоровьесберегающая педагогическая деятельность}

Выводы. Суммируя сказанное, Ж. В. Шарафуллина С. А. Уланова в своей работе выдвигают следующее определение здоровьесберегающей среды - это особый уклад деятельности образовательной организации, который 
поддерживает здоровый образ жизни ее субъектов и содействует их саморазвитию в обретении ценности здоровья.

Таким образом, можно сказать, что при разработанной стратегии, решающее влияние на процесс средовой обусловленности здоровьесбережения будет оказывать коммуникативно-технологический компонент, поскольку именно в нем заключены субъектно-психические ресурсы здоровьесберегающей среды. Взаимосвязь всех компонентов здоровьесберегающей среды и их согласованность составляют основу средовой детерминации здоровьесбережения.

\section{Список литературы}

1. Басов М.Я. Избранные психологические произведения. - М.: Педагогика. - 1975. - 432 с.

2. Климова Т.В. «Инновационные подходы к организации опытноэкспериментальной работы в дошкольном образовательном учреждении» Новосибирск: Изд. НГПУ, 2007. -С. 30-37.

3. Цибульникова, В. Е. Здоровьеформирующая и здоровьесберегающая среда как компонент образовательной среды школы / В. Е. Цибульникова. Текст: непосредственный // Наука и школа. 2018. № 1. С. 156-165).

4. Подгорная, О. Е. Проектирование здоровьесберегающего пространства общеобразовательной школы средствами личностно-ориентированного образования: специальность «Общая педагогика, история педагогики и образования»: автореферат диссертации на соискание ученой степени кандидата педагогических 122 наук / Подгорная О. Е.; Ростовский государственный педагогический университет. Ростов-на-Дону, 2005. 2; с15.

5. Сериков Г. Н., Сериков С. Г. Здоровьесбережение в гуманном образовании: моногр. Екатеринбург; Челябинск: Изд-во ЧГТУ, 1999. 242 с.

6. Волошина, Л. Н. Здоровьесбережение в системе дошкольного образования [Текст] / Л. Н. Волошина // Материалы региональной научнопрактической конференции «Образование и здоровье». - Белгород: Изд-во БелГУ, 2006. -С. 294 - 297.

7. Кузнецова, О.В. Подготовка педагогов к введению ФГОС / О.В. Кузнецова, Н.В. Дудырева // Управление начальной школой. - 2011. № $11 .-$ C. 15

8. Шарафуллина Ж. В., Уланова С. А., Ярославльский педагогический вестник 2013. - С 213. 
9. Андриади И.П. «История образования и педагогической мысли», «Вестник» № 1 (19) Москва 2008, - С.5

10. Э.М. Казин, Н.Э. Касаткина, Т.Н. Семенкова, «Психологопедагогические проблемы формирования культуры здоровья обучающихся» Вестник ТГПУ (TSPU Bulletin). 2011. 10 (112)

11. Касимов Р.А. «Формирование регионального здоровьесберегающего образовательного пространства» [Текст] / Р.А. Касимов. - М.,2007. - 162 с.

12. Берулава М.Н. «Гуманизация образования:проблемы и перспективы. Бийск», 1995. -31с.

13. Министерство образования РФ. Федеральный закон от 29 декабря 2012 г. N 273-Ф3 «Об образовании в Российской Федерации».

\section{References}

1. Basov M.Ya. Selected psychological works. - M.: Pedagogy. - 1975- - 432 p.

2. Klimova T.V. «Innovative approaches to the organization of experimental work in a preschool educational institution» Novosibirsk: Publishing House of NGPU, 2007. -pp. 3037.

3. Tsybulnikova V.E., Health-forming and health-saving environment as a component of the educational environment of the school / V. E. Tsybulnikova. Text: direct // Science and school. 2018. No. 1. pp. 156-165).

4. Podgornaya O.E., Designing the health-saving space of a comprehensive school by means of personality-oriented education: specialty "General pedagogy, history of pedagogy and education": abstract of the dissertation for the degree of Candidate of pedagogical sciences 122 / Podgornaya O. E.; Rostov State Pedagogical University. Rostov-on-Don, 2005. 2; c15.

5. Serikov G. N., Serikov S. G. Health care in humane education: monogr. Yekaterinburg; Chelyabinsk: Publishing house of CHSTU, 1999. 242 p.

6. Voloshina L.N. , Health care in the system of preschool education [Text] / L. N. Voloshina // Materials of the regional scientific and practical conference "Education and health". Belgorod: Publishing House of BelSU, 2006. pp. 294 - 297.

7. Kuznetsova O.V., Preparation of teachers for the introduction of the Federal State Educational Standard / O.V. Kuznetsova, N.V. Dudyreva // Management of primary school. - 2011. - No. 11. - p. 15

8. Sharifullina J.V., S.A. Ivanov, in Jaroslaw pedagogical Bulletin 2013. 213. 
9. Andriadi I.P., "History of education and pedagogical thought", "Bulletin" № 1 (19) Moscow, 2008, P 5.

10. Kazin.E.M., N. Uh. Kasatkina, T. N. Semenkov, "Psychological and pedagogical problems of formation of culture of health of students," Bulletin of Tomsk state pedagogical University (TSPU Bulletin). 2011. 10 (112).

11. Kasimov R.A. , Formation of a regional health-saving educational space [Text] / R.A. Kasimov. -M., 2007. - 162 p.

12. Berulava M.N. "Humanization of education:problems and prospects. Biysk", 1995. -31s.

13. Ministry of Education of the Russian Federation. Federal Law No. 273-FZ of December 29, 2012 "On Education in the Russian Federation".

(C) Г.А. Компанец, 2021 